\title{
Revealing side effects of quota rules on group cooperation
}

\begin{abstract}
Angela R. Dorrough ${ }^{1,2}$
dorrough@coll.mpg.de

Manuela Barreto 4,5
m.barreto@exeter.ac.uk
\end{abstract}

Andreas Glöckner ${ }^{1,6}$

andreas.gloeckner@

fernuni-hagen.de

\footnotetext{
${ }^{1}$ Max Planck Institute for Research on Collective Goods, Bonn

Kurt-Schumacher-Str.10

53113 Bonn, Germany

${ }^{2}$ University of Siegen

Adolf-Reichwein-Str.2

57068 Siegen, Germany

${ }^{3}$ University of Bonn

Regina-Pacis-Weg 3

53113 Bonn, Germany

${ }^{4}$ Washington Singer Laboratories, Psychology

College of Life and Environmental Science

University of Exeter

Exeter, EX4 4QG, UK

${ }^{5}$ Lisbon University Institute (CIS/ISCTE-IUL)

Av. das Forças Armadas

1649-026 Lisboa, Portugal

${ }^{6}$ University of Hagen

Institut für Psychologie

Universitätsstr. 27

58084 Hagen, Germany
}

Author Note

Angela R. Dorrough and Monika Leszczyńska share first authorship of this article.

Correspondence concerning this paper should be addressed to: Monika Leszczyńska, Max Planck Institute for Research on Collective Goods, Kurt-Schumacher-Str.10, D-53113 Bonn, e-mail: ziolkowska@coll.mpg.de 


\title{
SIDE EFFECTS OF QUOTA RULES
}

\section{Revealing side effects of quota rules on group cooperation}

\author{
Abstract \\ The quota rule in employment is a legal tool to promote gender equality in professions and \\ positions where women are underrepresented. An accompanying assumption is that gender \\ diversity positively affects one of the aspects of team performance in form of group cooperation. \\ However, it is unclear whether this positive effect can be achieved if diversity increases due to a \\ quota rule. In two fully incentivized experiments involving a real-effort task $\left(N_{1}=188\right.$ and $N_{2}=$ \\ 268), we examined the impact of quotas as compared to performance-based promotion on group \\ cooperation. We thereby categorized participants either with regard to gender or to an artificial \\ category that was randomly assigned. Cooperation within groups declined when promotion was \\ based on quota compared to performance-based promotion, irrespective of the categorization \\ criterion. Further analyses revealed that this negative effect of quota rules on cooperation is not \\ driven by procedural fairness perceptions or expectations about performance of the promoted \\ group member. Implications of the results for the implementation of equality and diversity \\ initiatives are discussed.
}

Keywords: affirmative action; group processes; gender quota; cooperation; diversity; gender equality

JEL: C92, D23, J78, M14

PsycINFO: 3020, 3660 


\section{SIDE EFFECTS OF QUOTA RULES}

\section{Revealing side effects of quota rules on group cooperation}

\section{Introduction}

Despite significant advances during the past decades, a large gap exists between the representation of men and women in the labor force. The underrepresentation of women is particularly striking in high-profile business positions, such as company executives or board members (International Labour Organization, 2012). The facts are clear and the social and economic importance of achieving gender equality in the workplace is undisputable. Yet, there is a lack of consensus regarding the types of measures that should be applied in order to introduce gender equality in the workforce. A variety of measures have been proposed, from those that aim to address specific obstacles commonly faced by women (such as improved childcare provisions) to those that focus more directly on the promotion of women, be it through the provision of additional training, or through the implementation of mandatory quotas. ${ }^{1}$ From among the various gender equality and diversity policies, the introduction of mandatory gender quotas has attracted the greatest controversy. Until recently, quotas for women were mainly restricted to political participation (i.e., in national parliaments, Inter-Parliamentary Union, 2014). However, quotas have now become a popular strategy for increasing women's representation in other sectors as well, such as on corporate boards (Catalyst, 2014).

On the one hand, policymakers who propose the introduction of a gender quota in public agencies and private organizations do so because this strategy guarantees the increase in women's representation in a specific position or domain within a relatively short period. Besides this immediate benefit, legislators claim that introducing quotas for boards of directors in listed

\footnotetext{
${ }^{1}$ Measures undertaken in order to achieve equality for members of groups that have been disadvantaged in the past are known under the term 'affirmative action' or 'positive action'. For a definition, see European Commission, International perspectives on positive action measures. A comparative analysis in the European Union, Canada, the United States and South Africa, 2009.
} 


\section{SIDE EFFECTS OF QUOTA RULES}

companies will bring additional benefits in the form of increased corporate performance. For example, a report from the European Commission points out that the "presence of women [on boards] contributes to improving corporate governance, team performance and the quality of decision-making" (European Commission, 2012, p.13). A crucial—but as yet underresearched - aspect of this debate is whether or not these benefits of gender diversity can indeed be achieved through the implementation of quotas. In particular, it is as yet unclear whether or not a quota procedure positively affects an important feature of group performance, namely cooperation. In this paper, we report two experiments carried out to test whether or not this is the case by examining the effect of quotas on cooperation, understood as people's actions that "promote the goals of the group" (Tyler \& Blader, 2000 p. 3) when individual outcomes depend upon the performance of the other group members (Wageman \& Baker, 1997). In particular, we test how purely performance-based vs. category-based (quotas) promotion procedures influence group cooperation between incumbent members of a group and newcomers.

Numerous experimental studies have researched the impact of gender diversity on group decision making, i.e., in entrepreneurship tasks (Hoogendoorn, Oosterbeek, \& van Praag, 2013) and different aspects of performance, such as generosity (Dufwenberg \& Muren, 2006). Furthermore, it has been experimentally investigated how gender diversity influences group cooperation using both - effort choices (Ortmann \& Tichy, 1999) and real effort tasks (IvanovaStenzel \& Kübler, 2011). Similar to these studies we focus on group cooperation. However, differently from previous research, we do not examine the impact of gender diversity on cooperation. Instead, we investigate how group cooperation is influenced by quota-based promotion procedures compared to performance-based procedures. Previous research on the effects of affirmative action has focused on individual task performance, job satisfaction, and 


\section{SIDE EFFECTS OF QUOTA RULES}

task selection (for overviews, see Crosby, Iyer, \& Sincharoen, 2006; Heilman \& Alcott, 2001), but did not investigate group performance, or cooperation within teams. More recent research has provided relevant insights into this problem (Balafoutas \& Sutter, 2012; Mollerstrom, 2012), but has left important questions unanswered, some of which are addressed in this project. Specifically, we address the following questions:

1. Does group cooperation decrease when promotion is based on a quota rule as compared to performance?

2. Does a quota-based promotion affect group cooperation differently when it is applied to gender than when it is applied to an artificial and randomly assigned category?

3. Is a quota-based promotion into a high-status group ${ }^{2}$ perceived as less fair than a performance-based procedure?

4. If so, is this effect of promotion rule mediated by differences in fairness perceptions?

\subsection{Previous findings concerning the effects of affirmative action}

Prior research has mainly focused on how different affirmative action policies in general, and quota rules in particular, are perceived and what impact they have on an individual's behavior. A core finding in this literature is that affirmative action can undermine the self-esteem of its beneficiaries (women), as well as diminish their image in the eyes of non-beneficiaries (men). In particular, compared to women who were selected purely on the basis of performance, women selected as a result of affirmative action evaluated their own leadership abilities more poorly (Heilman, Lucas, \& Kaplow, 1990), chose to perform less demanding tasks (Heilman,

\footnotetext{
${ }^{2}$ In this context, a "high-status group" is understood to be a group that is characterized by greater prestige, higher earnings, or higher career level.
} 


\section{SIDE EFFECTS OF QUOTA RULES}

Rivero, \& Brett, 1991), assumed that others would disregard their competence (Heilman \& Alcott, 2001), and were indeed seen as less competent by others (Heilman, Block, \& Lucas, 1992). It is important to note, however, that no such detrimental effects were shown when it was clear that performance is one of the criteria used in affirmative action decisions, suggesting that negative effects of affirmative action are heavily dependent on the assumption that merit plays no role in these decisions (Heilman, Block, Martell, \& Simon, 1989; Unzueta, Gutiérrez, \& Ghavami, 2010). Furthermore, recent research revealed that affirmative action receives lower acceptance if one can directly identify individuals disadvantaged by the measure (Ritov \& Zamir, 2014). Research carried out outside laboratory settings reports contradictory results. Specifically, while some studies do not reveal any detrimental consequences of affirmative action on interpersonal and self-perceptions (e.g., Plous, 1996; Taylor, 1994), it has also been found that female managers who believed they were selected because of their sex, reported lower job commitment and satisfaction (Chacko, 1982).

Findings concerning behavioral reactions are partially inconsistent as well. Nacoste (1990, 1996; Nacoste \& Hummels, 1994) proposed that policies that are implemented in ways considered to be unfair are likely to have negative effects on social interactions, such as the willingness of individuals to interact with other members of their group. Two recent studies provide relevant, but contradictory evidence for this proposition. Balafoutas and Sutter (2012) focused on how affirmative action affected coordination and productivity in groups of women who were promoted and men who became worse off as a result of the preferential treatment given to women. These authors found an increase in team productivity under a quota rule as compared to a treatment in which promotion was based on performance. However, the question 


\section{SIDE EFFECTS OF QUOTA RULES}

remains as to how a quota rule affects the cooperation of the group that is newly created as a result of a quota-based promotion procedure.

Mollerstrom (2012) addressed this question by examining behavior in a high-status group composed of members who were selected according to their prior performance and members chosen on the basis of a quota rule. Contrary to the results of Balafoutas and Sutter (2010), cooperation in this newly formed group was lower if some of the members were selected on the basis of a quota rule, compared to a condition in which all members were selected according to their performance on a prior task. However, this study used artificially created categories based on a minimal group paradigm (Tajfel, 1970; Tajfel \& Turner, 1979; see also Brewer, 1993) instead of a natural social category with a history of disadvantage, such as gender or race. Specifically, in Mollerstrom's (2012) study, groups were randomly created and designated by color names, such as 'orange' and 'purple'. Although these studies differ in other ways as well, it is possible that this difference - applying quotas to minimal groups or to groups with greater personal and historical significance - might explain the divergence in findings between Balafoutas and Sutter (2010), on the one hand, and Mollerstrom (2012), on the other. Indeed, it is possible that quotas are better received when the category based on which some individuals receive preferential treatment is historically disadvantaged in the context where quotas are applied, such as women in boardrooms. To examine this possibility directly, we compare responses to the implementation of gender quotas with responses to quotas implemented in minimal groups.

\subsection{Quota rules, procedural fairness, and meritocracy}




\section{SIDE EFFECTS OF QUOTA RULES}

Objections to affirmative action can derive from both distributive and procedural fairness considerations $^{3}$ (Nacoste, 1996). However, affirmative action policies have been found to be perceived mainly in relation to procedural fairness (Cohen-Charash \& Spector, 2001). According to Nacoste (1996) what drives people's procedural fairness perception of affirmative action is the weight the procedure gives to the "contribution-related" (i.e. education) versus "noncontributionrelated" features (i.e. gender). Consequently, procedural fairness considerations are also likely to drive responses to quota rules.

According to the group engagement model (Tyler \& Blader, 2000, 2003), group members pay close attention to procedural fairness within their group. Group members derive motivation to favor their group or not, depending on these procedural fairness judgments (De Cremer, Tyler, \& den Ouden, 2005; Blader \& Tyler, 2009). Since procedural fairness affects the group members' willingness to cooperate with fellow group members, or work on behalf of the group, we expect that cooperation might be reduced after the implementation of a quota rule due to its negative effect on perceived procedural fairness.

Quota-based selection procedures that do not explicitly take into account individual performance are likely to be perceived as unfair due to widespread beliefs in meritocracy. Meritocracy beliefs constitute the conviction that unequal economic status is and should be earned by individual merit alone (e.g., Kluegel \& Smith, 1986). These beliefs, even when erroneous, are dominant in Western societies, partly because they fulfil a fundamental need to believe that the world is a just and fair place (Lerner, 1980). Hence, they are the default for

\footnotetext{
${ }^{3}$ Procedural fairness refers to the evaluation of the fairness of processes through which the outcomes are achieved. The following criteria are usually named as relevant for perceptions of procedural fairness: Neutrality (unbiased, honest decisions), status recognition (treatment with politeness, dignity, respect), and trustworthiness (decision makers concern for the needs of others) (see Tyler, Degoey, \& Smith, 1996).
} 


\section{SIDE EFFECTS OF QUOTA RULES}

perceiving the world (e.g., Barreto \& Ellemers, 2015). Therefore, although quota systems aim to correct for the absence of meritocratic treatment (just like other forms of affirmative action), given the default belief in meritocracy, they are likely to be regarded as unfair, particularly when they are applied explicitly, irrespective of individual performance. Furthermore, it has been found that individuals have the tendency to defend the current system (i.e. system justification, Jost \& Banaji, 1994). This tendency might be manifested in meritocratic ideology (Jost, Pelham, Sheldon, \& Sullivan, 2003).

If beliefs in meritocracy constitute the main process governing perceptions of quota rules, then we should expect individuals to oppose quota systems, irrespective of whether these refer to gender or to any other group, such as a randomly created artificial group. Nevertheless, it is possible that additional processes play a role in responses to quota systems. Such processes may indeed lead to different reactions, depending on whether quotas are based on gender or on artificially created (or socially meaningless) categories. For example, research on categorization threat (Branscombe, Ellemers, Spears, \& Doosje, 1999) has shown that individuals resent imposed categorical treatment, even when it affords them with an advantage (Barreto, Ellemers, Scholten, \& Smith, 2010). Indeed, categorical treatment that is seen as contextually inappropriate leads to lower identification and less cooperation with the group in which one is being externally categorized (Barreto \& Ellemers, 2003). Although this can happen with any group membership, responses are likely to be stronger when the imposed categorical treatment refers to a social category that has meaning outside of the experimental context, especially when it tends to be more chronically disadvantaged. A similar argument is made in the literature on responses to discrimination. In this case, group-based treatment (discrimination) is found to have more negative effects when it pertains to social groups that are frequently discriminated against (e.g., 


\section{SIDE EFFECTS OF QUOTA RULES}

women) than to social groups that are rarely discriminated against (e.g., men; Schmitt \& Branscombe, 2002).

In sum, the available evidence does not allow us to draw firm predictions regarding potential effects of categorization type (gender versus an artificially created category) on responses to quota systems. However, comparing responses to quota systems based on gender with responses to quota systems based on an artificially created category allows us to examine more closely whether reactions towards quota systems are driven merely by beliefs in the importance of merit, or also by the broader social significance of such preferential treatment and, if so, exactly how they shape behavior.

\subsection{Hypotheses}

The present research focuses on the effects of quota systems on group cooperation, specifically on cooperation within the high-status group into which the quota or performance

allows entry. As such, we restrict our hypotheses to the incumbent and new members of the highstatus group.

H1: The members of the high-status group are expected to show reduced group cooperation after a promotion based purely on quota, as compared to a promotion based purely on performance.

H2a: Members of a high-status group are expected to perceive promotion based purely on quota as less fair than promotion based purely on previous performance.

H2b: The reduction of group cooperation is expected to be mediated by fairness perceptions.

We also examine whether the effects of quotas on fairness perceptions and group cooperation differ depending on whether quotas are based on gender or on experimentally 


\section{SIDE EFFECTS OF QUOTA RULES}

created categories. In light of previous research, both outcomes are possible. We therefore decided to specify the null hypothesis for the interaction between categorization criterion (gender or experimentally created category) and promotion procedure (quota- or performance-based) and neutrally test whether it must be rejected or not.

H3: Quota rules are expected to lead to less cooperation and be perceived as less fair than performance-based promotion, irrespective of whether quotas are based on gender or on artificially created categories.

\section{Experiment 1}

With Experiment 1 we investigated the effects of two different promotion rules: Promotion based on categorization criterion (quota rule) or previous performance in a real-effort task (performance rule). We additionally manipulated the categorization criterion by introducing categorization based on gender or on experimentally created category (i.e. color assignment). We assessed group cooperation before and after the promotion rule was applied. Additionally, we examined fairness perception of the different procedures.

\subsection{Materials and methods}

\subsubsection{Design and participants}

Participants were randomly assigned to the four conditions of a 2(categorization criterion: gender vs. artificial category) x 2(promotion rule: performance vs. quota) between-participants factorial design. One hundred eighty-eight participants, mostly students at the University of Bonn (age: $M=24.74, S D=6.5 ; 50 \%$ female) with heterogeneous fields of study, were recruited from the MPI Decision Lab subject pool via the online recruitment tool ORSEE (Greiner, 2004, 2015). Participants interacted with each other in groups of four, and usually 12 individuals took 


\section{SIDE EFFECTS OF QUOTA RULES}

part in each of the 19 experimental sessions. Due to occasional no-shows, only eight participants (two groups) took part in some sessions, resulting in valid data from 11 to 13 groups per condition. Each session lasted about 70 minutes. In all four conditions, participants performed an incentivized slider task. Participants' total payments ranged from 3.70 to 22.50 Euros (approx. USD 4.17 to 27.65). ${ }^{4}$ The experiment was programmed in z-Tree (Fischbacher, 2007).

\subsubsection{Materials and procedure}

Upon arriving at the laboratory, participants were randomly assigned to separate cubicles. They were instructed that communication between participants was forbidden throughout the experiment and that the experiment consisted of two parts. First, instructions describing the rules of the first part were distributed (on paper). ${ }^{5}$ After participants had answered three control questions, their answers were checked by the experimenters. In case of at least one incorrect answer, participants were asked to reread the instructions and to try again. Afterwards, participants filled out a demographic questionnaire. Next, they were assigned to groups of four. In the gender conditions (gender performance and gender quota) each group consisted of one randomly drawn female and three randomly drawn male participants. In the color conditions (color performance and color quota), participants were first randomly assigned a color (orange or green) and next randomly divided into groups of four (three orange and one green participant in each group). Afterwards, each group of four was split into two-person subgroups (high-status and low-status subgroups), in which participants performed the first part of the experiment. This means that half of the participants started in a privileged high-status group. The remaining half of

\footnotetext{
${ }^{4}$ In addition to the performance contingent reward $(M=10.90 €$, approx. USD 12.29), participants received $1 €$ (approx. USD 1.13) fixed payment for an online Social Dominance Orientation questionnaire they filled out at least 12 hours before coming to the laboratory.

${ }^{5}$ The experimental instructions as well as all other files (data, experimental program, analyses) can be retrieved from https://osf.io/t4fgu/
} 


\section{SIDE EFFECTS OF QUOTA RULES}

the participants started in a low-status group. The differences in status were introduced through an exchange rate of points earned in the experimental task. Each point obtained by a member of a high-status group was worth 16 cents, whereas members of a low-status group received 8 cents for each point. Thus, members of low-status groups were discriminated against with regard to wage for performing exactly the same task as members of the high-status groups.

The high-status group consisted of two male (two orange) participants and the low-status group consisted of one male (one orange) and one female (one green) participant. The male (orange) participants had a chance of $2 / 3$ of being assigned to the high-status group, whereas the female (green) participants were always assigned to the low-status group. Thus, female (green) participants had no chance of being initially assigned to the high-status group. This way in the gender condition females were discriminated against (all were placed in the low status group). In the artificial category conditions, two color groups were created (green and orange) and participants randomly categorized as 'green' were discriminated against (all were placed in the low-status group). In the color conditions, participants were provided with information on the color they were assigned to and the color of the other subgroup member. In the gender conditions, participants were provided with information on the gender of the other subgroup member.

In the experiment, participants completed a slider task (Gill \& Prowse, 2012, 2013). Participants were presented with 48 sliders on the screen. Each slider ranged from 0 to 100 . Participants were instructed that their task was to adjust sliders from the initial position at 0 to the value of 50. They had 120 seconds for this task and could move the slider bar by clicking on the sides of the bar or by dragging the slider along the bar, which moved the slider by increments of 1. Since previous research has found systematic differences between hypothetical and real 


\section{SIDE EFFECTS OF QUOTA RULES}

social interactions (e.g. Vlaev, 2012), we fully incentivized the slider task to enhance external validity: For each correctly solved slider (that is, for each slider that was placed exactly at the value of 50) participants earned one point. The slider task has one additional advantage: Previous studies did not observe gender differences in individual performance on this task (Gill \& Prowse, 2013; Gerhards \& Siemer, 2014; Lindner, 2014). This feature is important to our research since we aimed at implementing a gender-neutral task.

The first part of the experiment included three phases in which the slider task was completed, that is a practice trial, and two phases that were relevant for payment: One with the individual and one with the group payment scheme (in randomized order). After each phase, participants received feedback concerning the number of sliders solved. In the individual scheme, payment depended solely on individual performance. Thus, it served as a benchmark for individual skills and learning. In the group scheme, the number of sliders solved by the two members of a subgroup were summed up, multiplied by 1.2 , and divided evenly between the subgroup members. We implemented this multiplier to reflect additional benefits obtained through group work. Hence, both members of each subgroup (i.e., high-status or low-status group) could additionally profit from their contribution. After completing the slider task in both payment phases, participants received feedback about their payoffs (in the individual payment phase, in the group payment phase, and total payoff).

As soon as the first part was over, the instructions for the second part were distributed. Participants read that one of the low-status subgroup participants would now switch to the highstatus subgroup and replace a randomly chosen high-status subgroup participant, who in turn would switch to the low-status subgroup, in order to keep the group size constant. This way a possibility of being promoted from the low-status to the high-status group was introduced. The 


\section{SIDE EFFECTS OF QUOTA RULES}

promotion rule varied depending on the experimental condition. In the performance-based condition, the low-status subgroup member who switched to the high-status subgroup was chosen on the basis of the average number of sliders solved in the preceding individual and group payment phases. The participant with more sliders solved was promoted to the high-status subgroup (a random draw was conducted in case of a tie), irrespective of his/her color or gender. In the quota conditions, a female (green) participant was chosen to be promoted to the highstatus subgroup. In this case, performance in the first part of the experiment was irrelevant for the promotion. After reading the second part of the instructions and answering a control question regarding the promotion procedure, ${ }^{6}$ participants were informed (on the screen) about whether they would switch to the other subgroup or remain in their initial subgroup. They were also reminded of what constituted the basis for promotion (performance, gender, or color). Although participants who stayed in the high-status subgroup were well aware of what promotion rule had been used to recruit the new member, they were not informed about the exact performance of their new subgroup member. The new subgroup members were also not informed about the exact performance of the incumbent subgroup member. Next, as in the first part of the experiment, participants solved the slider task once with the individual and once with the group payment scheme (again, the order was randomly determined). The payment for each point obtained in the slider tasks followed the same rule as in the first part—high-status group members received 16 cents per point, while low-status group members received 8 cents per point. At the end of the second part, participants received information about their payoffs in this part of the experiment (again separately for individual and group payment scheme, and total payoff). Afterwards,

\footnotetext{
${ }^{6}$ The control question was a multiple choice question. Irrespective of the condition, there was always one option describing the quota-based promotion procedure and one option describing the performance-based promotion procedure. In this way, participants were made aware of other possible promotion procedures.
} 


\section{SIDE EFFECTS OF QUOTA RULES}

participants filled out a questionnaire in which they were explicitly asked about the extent to which they perceived the promotion procedure as fair. To assess perceived fairness of the promotion procedure, we included a questionnaire based on Tyler and Blader (2000). The questionnaire included items such as "The rules and procedures were equally fair to everyone", "The participants were treated with dignity", "How fair was the outcome of the promotion procedure?" Questions were answered on seven-point Likert-type scales, with higher scores representing perceptions of the procedure as fairer. ${ }^{7}$ The resulting questionnaire consisted of a scale measuring the formal quality of decision-making (four items; Cronbach's alpha $=0.76$ ) and another scale measuring the formal quality of treatment (three items; Cronbach's alpha $=0.84$ ). Furthermore, we included a scale on distributive fairness in order to control for potential differences in distributive justice perceptions (two items; Cronbach's alpha $=0.81$ ). ${ }^{8}$

Finally, participants were informed about their total payments in both parts of the experiment and asked to enter individually a separate room, where they received their payments in private.

\subsection{Results}

Since our hypotheses refer to the behavior of the members of the high-status group, the analyses focus on the responses of a subgroup of participants consisting of an incumbent member of the high-status group and a new member originally stemming from the low-status group.

\footnotetext{
${ }^{7}$ In the experiment, participants answered the fairness questionnaire with an inverted scale where 1 indicated the fairest and 7 the most unfair judgment. For the sake of a more intuitive understanding of the results, we inverted the scale in all analyses.

${ }^{8}$ We additionally examined whether responses to quota systems based on gender or on artificially created groups are affected by chronic tendencies to endorse, desire, and support social hierarchies, that is, social dominance orientation (Sidanius \& Pratto, 2001). The analyses revealed no significant effects of this measure. For details of these analyses, please contact the lead authors.
} 


\section{SIDE EFFECTS OF QUOTA RULES}

Therefore, the total number of participants whose responses are relevant to our hypotheses is half $(N=94)$ of the total number of participants who took part in Experiment $1(N=188)$.

\subsubsection{Performance and cooperation}

Two participants solved no slider during the entire experiment and one participant solved no slider only in the first part of the experiment, which most probably is a result of a misunderstanding of the task. These participants were excluded from all following analyses. Thus, the total number of participants entering the analysis is $91 .^{9}$ Averaged across all parts and conditions of Experiment 1, participants solved a total of $87.9(S D=19.3)$ sliders (excluding practice trial), which amounts to the average of $21.9(S D=4.8)$ sliders per phase. In the color conditions, the difference between the average number of sliders solved by male and female participants was not statistically significant (men: $M=22.9, S D=5.4$; women: $M=21.54, S D=$ 3.97; Mann-Whitney test: $z=1.31, p=.18$ ), confirming the gender neutrality of the task. In the gender conditions, however, female participants solved on average fewer sliders than male participants (men: $M=23.11, S D=4.96$; women: $M=19.60, S D=5.47$; Mann-Whitney test: $z=$ 2.13, $p=.03$ ). In line with research on the effects of disadvantage on performance (e.g., Barreto, 2014 for a review), this difference is likely to reflect the negative motivational effects of the gender disadvantage induced at the start of the study.

Our set of hypotheses concerns the effects of quota on cooperation in the second part of the experiment (i.e., after promotion). According to the definition of cooperation adopted in this article, we assumed that the goal of the group in the experiment is to maximize the sum of the number of sliders solved by the two members of the group. Given this goal, a cooperative act of

\footnotetext{
${ }^{9}$ Including these participants in the sample does not change the pattern of the results.
} 


\section{SIDE EFFECTS OF QUOTA RULES}

each member would be to solve as many sliders as possible in the group payment scheme. The number of sliders solved in the individual payment scheme was regarded as a benchmark for the maximum number of sliders one is able to solve within 120 seconds. Thus, the participants' willingness to cooperate was operationalized as the difference in number of sliders solved in the group payment scheme and number of sliders solved according to the individual payment scheme. This difference is referred to in the following as the 'cooperation score'. A negative cooperation score indicates free-riding, whereas a positive cooperation score implies cooperation. The cooperation score controls for any heterogeneity in skills and learning, since performance in the individual payment scheme is included in its calculation. To test our hypotheses, we focused on a change in cooperation scores between the first and second part of the experiment (before and after promotion). The cooperation score in the first part of the experiment was subtracted from the cooperation score in the second part. Positive values indicate either an increase in cooperation or a decrease in free-riding, whereas negative numbers indicate a decrease in cooperation or an increase in free-riding. Individual average cooperation scores for all experimental conditions are displayed in Table 1.

\section{[Insert Table 1]}

Figure 1 displays the results concerning group means of the change in cooperation scores by experimental conditions.

\section{[Insert Figure 1]}

We conducted an OLS regression analysis, predicting this change in the cooperation score by promotion rule (variable quota $\operatorname{coded} 0=$ performance, $1=$ quota), categorization criterion (variable color coded $0=$ gender, $1=$ color), and their interaction (variables centered). 


\section{SIDE EFFECTS OF QUOTA RULES}

To control for interdependencies between participants, we used a cluster correction for standard errors at the group level. Additionally, a task order indicator was included as a control variable to account for general learning effects over time. The results of the analysis are displayed in Table 2 (Model 1).

[Insert Table 2]

In line with hypothesis 1 , we found a marginally significant difference in the change of cooperation score between performance-based as compared to quota-based promotion, $\mathrm{b}=-1.68$, $t(43)=-1.87, p=.07$. Although not statistically significant ${ }^{10}$, cooperation tended to increase in the performance condition (positive change in cooperation score) but tended to decrease in the quota condition (negative change in cooperation score) as can be seen from the column means in Table 1. Jointly, these two tendencies resulted in the overall marginally significant impact of the promotion procedure on the change in cooperation score.

Neither the main effect of categorization criterion (color vs. gender), $b=0.61, t(43)=0.69, p=$ .50 , nor the interaction reached conventional significance levels, $b=2.18, t(43)=1.22, p=.23$. Simple effects revealed that the change in cooperation score differs significantly between quotabased and performance-based promotion in the gender conditions, $F(1,46)=6.94, p=.02$, but not in the color conditions, $F(1,46)=0.22, p=.64$.

\subsubsection{Perceived fairness}

\footnotetext{
${ }^{10}$ Using a Wilcoxon signed rank test we compared the group means of the change in cooperation score against zero separately for the quota and the performance conditions. None of the tests reached conventional level of statistical significance (all $\mathrm{z}<1.73$ all p-values $>.08$ ).
} 


\section{SIDE EFFECTS OF QUOTA RULES}

In order to test our hypotheses $2 \mathrm{a}$ and $2 \mathrm{~b}$, we conducted an OLS regression predicting perceived procedural fairness by promotion rule (quota vs. performance), categorization criterion (color vs. gender), and their interaction (variables centered).

\section{[Insert Table 3]}

Results are displayed in Figure 2 and summarized in Table 3 (Model 1). We observed no main effect of a quota rule, as compared to a performance rule, $b=-0.14, t(88)=-.52, p=.60$. Hence, the results provide no support for hypothesis $2 \mathrm{a}$ assuming higher perceived fairness for performance-based promotion. Promotion rules were perceived as more fair when categorization was based on an artificially created group than when it was based on gender, $b=0.92, t(88)=$ $3.38, p=.001$. We additionally observed an unexpected interaction between promotion rule and categorization/discrimination criterion, $b=1.16, t(88)=2.14, p=.04$. Hence, the null hypothesis 3 assuming no influence of categorization criterion was rejected. Simple effects revealed that quota rules were perceived as less fair (albeit marginally significant) than performance-based promotion in the gender conditions, $F(1,87)=3.54, p=.06$, but not in the color conditions, $F(1$, $87)=1.22, p=.27$.

\section{[Insert Figure 2]}

In sum, although the quotas imposed in this study did not comply with meritocracy principles, irrespective of the categorization criterion, they were only seen as less fair than performance-based promotion when the categorization was based on gender rather than on an artificially created category.

According to hypothesis $2 \mathrm{~b}$, the effect of the promotion rule on cooperation should be mediated by fairness perceptions. However, the distinct patterns of findings for these two 


\section{SIDE EFFECTS OF QUOTA RULES}

measures suggest that this is not the case. Indeed, an OLS regression predicting a change in cooperation score with fairness perceptions as an independent variable and task order indicator as a control variable did not reveal a significant effect, $b=0.171, t(44)=0.67, p=.51$. Similar results were obtained when conducting the same OLS regression separately for conditions in that the procedure was found to be comparatively unfair (i.e. the gender conditions). The influence of fairness perception on a change in the cooperation score was far from significant $(p>.43)$ in both conditions. Thus, the necessary conditions for mediation analysis have not been met (Baron \& Kenny, 1986). Hence, hypothesis $2 b$ was not supported by our data. The observed effect of promotion rules on group cooperation was not mediated by fairness perceptions.

\subsection{Discussion}

With Experiment 1, we systematically investigated the effects of one of the measures aimed at reducing gender inequality in the workplace — gender quotas — on team cooperation. One of the positive effects argued by proposers of gender quotas is their potential to improve team performance. Our results suggest that this idea is misguided in contexts where team performance is reliant on cooperation measured by people's individual actions to promote the goals of the group, at least when no further information is provided that justifies the use of quotas.

We found some potential side effects of quota rules at the behavioral level. Our findings showed that the participants' willingness to exert effort on behalf of the group (a willingness either to free-ride less or to cooperate more) is negatively influenced at the marginally significant level by promotion based on a quota rule, as compared to performance-based promotion. 


\section{SIDE EFFECTS OF QUOTA RULES}

Quota-based promotion was perceived as less fair than promotion based on performance only when the quota procedure was based on gender, and not when it was based on an experimentally created category. That is, our participants perceived a preferential treatment based on an experimentally created group (that had initially been disadvantaged) as equally fair as a performance-based rule. Contrary to our hypothesis, the effect of quota on cooperation was not mediated by fairness perceptions.

Although we did our best to develop an adequate experimental paradigm to test our hypotheses, critical inspection of our design reveals some potential limitations. First, as the analyses are limited to the high-status group members, the number of participants that entered the analyses is only half of the full sample size of $N=188$. This allows us to detect group differences of a medium size with a power of $1-\beta=.67(d=.50, \alpha=.05$, two-tailed test; Faul et al., 2009). Therefore, a replication with a larger sample size would clearly be desirable to gain more certainty about the effects. Besides, the composition of men and women was different in the color conditions as compared to the gender conditions. Whereas nine male and three female participants took part in an experimental session of the gender conditions (or six male and two female participants in case of no-shows), women were oversampled in the color conditions. Therefore, we cannot rule out that the observed differences between color and gender conditions were at least partially a result of the different gender compositions in the experimental conditions. For example, men and women might differ in their reactions to the implemented promotion rules or the number of male and female participants in one experimental session might influence individuals' behavior.

Another potential limitation of Experiment 1 is that we did not assess expectations regarding the performance of the new group member promoted based on performance or quota 


\section{SIDE EFFECTS OF QUOTA RULES}

rule. In the quota conditions, participants did not receive any information regarding individual performance. Given a very low marginal cost of solving one slider, maximal performance should be rational in all cases. Therefore, from a classic rational-choice perspective, expectations are unlikely to be the sole explanation for the observed results. However, we cannot completely exclude the possibility that the incumbent person might have lower expectations regarding the number of sliders that the incoming person promoted by quota is able to solve (Heilman et al., 1992). Low expectations could lead the incumbent person to adjust her performance accordingly by solving fewer sliders in the group-payment phase.

Finally, although we found the hypothesized negative impact of quota rules on cooperation, we could not confirm the hypothesized mediation, that is, fairness perceptions of the promotion procedure did not predict change in cooperation. This might reflect the nature of the process, but it might also reflect the specific design features of this research. Some participants pointed out that it was not entirely clear from which point of view to judge procedural fairness since the promotion rule affected not only the person who was promoted, but also the person who had to leave the high-status group. Furthermore, although we told participants to focus on the promotion stage when filling out the fairness questionnaire, some participants might have read over this information as it was provided along with the remaining parts of the instructions. Thus, it is possible that people evaluated different aspects of the procedure when answering the fairness questionnaire.

\section{Experiment 2}

With Experiment 2, we aimed to replicate the effect of promotion rule on group cooperation as found in Experiment 1. Experiment 2 was conducted to address the above- 


\section{SIDE EFFECTS OF QUOTA RULES}

mentioned issues by ensuring equal gender composition in the gender and color conditions, increasing the sample size, and adding further questions to shed light on participants' perceptions of the situation.

\subsection{Materials and methods}

\subsubsection{Design and participants}

As in Experiment 1, participants were randomly assigned to the four conditions of a 2(categorization criterion: gender vs. artificial category) x 2(promotion rule: performance vs. quota) between-participants factorial design. Two hundred sixty-eight participants (age: $M=$ 22.2, $S D=5.4,26.5 \%$ female) were recruited in the same manner as in Experiment 1. Differently from our first experiment however, we kept the proportion of male and female participants about equal in all experimental conditions. Twelve or sometimes eight individuals took part in each of the 27 experimental sessions. Each session lasted about 70 minutes. Participants' total payments ranged from 3.80 to 26.30 Euros (approx. USD 4.28 to 29.65). ${ }^{11}$

\subsection{Materials and procedure}

The first two parts of Experiment 2 followed exactly the same procedure as in Experiment 1. We introduced two changes at the end of Experiment 2. First, we asked the incumbent participants of the high-status group about their expectations regarding task performance of the incoming group member. The estimation task took place in the second part of the experiment after participants conducted the slider task in both payment schemes. It was introduced before the information about payoffs was displayed, since this information would

\footnotetext{
${ }^{11}$ To ensure comparability with our first study, participants again filled out an online Social Dominance Orientation questionnaire before coming to the laboratory for which they received a fixed amount of $1 €$ (approx. USD 1.13) in addition to the performance contingent reward ( $M=11.80 €$, approx. USD 13.30).
} 


\section{SIDE EFFECTS OF QUOTA RULES}

have revealed the incoming group member's performance in the group payment scheme.

Participants had to indicate their estimate of the average number of sliders solved by the promoted group member in the preceding individual and group payment phases in the second part of the experiment. ${ }^{12}$ For each correct estimate participants received an additional payment of $1 €($ approx. USD 1.13).

Second, after the second part of the experiment participants filled out the fairness questionnaire that we used in Experiment 1. To make sure that participants' evaluation target was clear, participants answered the fairness questionnaire three times: (1) with regard to the overall procedure implemented to the group change, (2) with regard to the procedure implemented to the group member promoted from the low-status to the high-status group, and (3) with regard to the procedure implemented to the group member switching from the highstatus to the low-status group. ${ }^{13}$ Before each questionnaire participants were presented on a separate screen with a statement clarifying which procedure and group member should be evaluated in the following questions. In order to proceed to the questions, participants had to press an "OK" button.

\subsection{Results}

\footnotetext{
${ }^{12}$ To keep the design equal for all participants, all of them stated their expectations about all other members of the initial 4-person group. For example, the person who stayed in the high-status group gave an estimate for the person who was promoted to the high-status group, the person who switched to the low-status group, and the person who stayed in the low-status group.

${ }^{13}$ All scales showed reasonable reliability in our sample: basic questionnaire: formal quality of decision-making: Cronbach's alpha $=0.71$, formal quality of treatment: Cronbach's alpha $=0.86$, distributive fairness: Cronbach's alpha $=0.74$. Questionnaire for person who switched to the high-status group: formal quality of decision-making: Cronbach's alpha $=0.76$, formal quality of treatment: Cronbach's alpha $=0.88$, distributive fairness: Cronbach's alpha $=0.75$. Questionnaire for person who switched to the low-status group: formal quality of decision-making: Cronbach's alpha $=0.76$, formal quality of treatment: Cronbach's alpha $=0.88$, distributive fairness: Cronbach's alpha $=0.71$.
} 


\section{SIDE EFFECTS OF QUOTA RULES}

In Experiment 2, as in Experiment 1, we focused in the analyses on participants who were either promoted to the high-status group or stayed in the high-status group after the first part of the experiment. Therefore, the total number of participants whose responses were analyzed is $N=134$ and constitutes half of the total number of participants who took part in Experiment $2(N=268)$.

\subsubsection{Performance and cooperation}

One person did not solve any slider during the whole experiment. Therefore, the ultimate number of participants entering the analyses is 133. In Experiment 2, participants solved on average $91.5(S D=21.3)$ sliders in both parts of the experiment in total, which amounts to the average of $22.9(S D=5.3)$ per phase (excluding practice trial). As in Experiment 1, there was no difference in the average number of sliders solved by men and women in the color conditions (men: $M=23.01, S D=5.0$; women: $M=22.03, S D=4.98$; Mann-Whitney test: $z=0.49, p=$ .62) again supporting the gender neutrality of the task. Also similarly to Experiment 1 , in the gender conditions male participants solved on average more sliders than female participants (men: $M=24.27, S D=5.4$; women: $M=19.56, S D=4.75$; Mann-Whitney test: $z=3.96, p<$ .001 ), which might be a result of the gender disadvantage introduced at the beginning of the study.

Participants' willingness to cooperate was operationalized, as in Experiment 1, by calculating the 'cooperation score' for each participant. This was used to calculate a change in cooperation scores as our core dependent measure. Average change in cooperation scores for all experimental conditions in Experiment 2 are given in Table 4.

[Insert Table 4] 


\section{SIDE EFFECTS OF QUOTA RULES}

Figure 3 displays the results concerning the group means of change in the cooperation scores.

\section{[Insert Figure 3]}

Model 2 in Table 2 presents the results of an OLS regression analysis including the same variables as for the analysis of the Experiment 1 (see Model 1). Again, the change in cooperation score was predicted by promotion rule, categorization criterion, and their interaction. We included the task order indicator and clustered the standard errors at the group level.

In line with Experiment 1, we found a marginally significant difference in the change of cooperation score between performance-based as compared to quota-based promotion, $b=-1.56$, $t(63)=-1.86, p=.07$. As can be seen in Table 4 and similar to Experiment 1 , cooperation tended to increase in the performance condition but tended to decrease in the quota condition (both results not statistically significantly different from zero ${ }^{14}$, which jointly results in the overall effect of quota-based vs. performance-based promotion. This result is in line with hypothesis 1 and serves as a replication of Experiment 1. Both the main effect of categorization criterion and the interaction were again statistically non-significant.

As we used exactly the same experimental procedures in Experiments 1 and 2 for the different stages of the real-effort task, we conducted an overall analysis to generate best estimates concerning the behavioral effects (Model 3). An OLS regression analysis with the same specification as above but including the pooled data of Experiment 1 and 2 and an

\footnotetext{
${ }^{14}$ We compared group means of the change in cooperation score against zero using a Wilcoxon signed rank test separately for the quota and the performance conditions. The tests revealed statistically nonsignificant results (all $\mathrm{z}<$ 0.98 all p-values $>.11)$.
} 


\section{SIDE EFFECTS OF QUOTA RULES}

experiment dummy revealed a significant decline in cooperation score comparing performancebased to quota-based conditions, $b=-1.61, t(109)=-2.60, p=.01 .{ }^{15}$

\subsubsection{Fairness perception}

Figure 4 presents the results of the fairness perception questionnaire. From the left to the right it displays: (A) general fairness perception of the procedure implemented after the first part of the experiment, (B) fairness perception of the procedure implemented with regard to the person switching from the high-status subgroup to the low-status subgroup (degraded participant), (C) fairness perception of the procedure implemented with regard to the promoted participant.

\section{[Insert Figure 4]}

Table 3 reports the results of an OLS regression analysis predicting perceived procedural fairness from promotion rule, categorization criterion, and their interaction. Model 2, which refers to the overall fairness perception, revealed that - in contrast to hypothesis $2 \mathrm{a}$ - there was again no main effect of the type of promotion procedure (quota vs. performance) on its fairness perception, $b=$ $.02, t(130)=0.10, p=.92$. Furthermore, we found an unexpected marginally significant impact of the categorization criterion on the overall procedural fairness perception. The promotion procedure was generally perceived as marginally significantly fairer in the color conditions as compared to the gender conditions, $b=.45, t(130)=1.91, p=.06$. The unexpected interaction

\footnotetext{
${ }^{15}$ To check whether the negative effect of quota-based vs. performance-based promotion only applies to a specific role (incumbent vs. newcomer) we conducted OLS regression analyses for both experiments separately as well as for the pooled data predicting the change in cooperation score by promotion rule, categorization criterion, role of the high-status group member, and the interaction between role and promotion rule. The effect of promotion rule (quota vs. performance) on cooperation score remains unchanged.
} 


\section{SIDE EFFECTS OF QUOTA RULES}

effect from Experiment 1 was not replicated: There was no interaction between promotion procedure and categorization criterion in Experiment 2, $b=0.30, t(130)=0.64, p=.53$.

Experimental conditions did not affect the perception of the procedure implemented with respect to the degraded person (Model 3). Neither the main effects of promotion procedure, $b=-$ $0.01, t(130)=-0.06, p=.96$, nor categorization criterion, $b=0.23, t(130)=0.98, p=.33$, nor their interaction, $b=0.50, t(130)=1.04, p=.30$, reached conventional statistical levels of significance.

In contrast, as revealed in Model 4, when people judged the procedure with a focus on the promoted person, the promotion procedure based on quota was perceived as less fair than promotion based on performance, $b=-0.74, t(130)=-3.42, p=.001$. Hence, some support for hypothesis $2 \mathrm{a}$ is found, when individuals focus not on the overall procedure but on the promoted person only. Also, similarly to fairness perception of the overall procedure, the procedure implemented with respect to the promoted person was perceived by participants in the color conditions as fairer than in the gender conditions, $b=.47, t(130)=2.17, p=.03$. The interaction term was not significant.

Further analyses revealed that again, for each target of evaluation perceived fairness did not predict the change in cooperation score $(p>.59)$, providing no support for hypothesis $2 \mathrm{~b}$. The same result was obtained with pooled data (Experiment 1 and 2) conducting an OLS regression (standard errors clustered at the group level) on change in cooperation score and including the overall perceived fairness as a predictor variable and task order indicator as a control variable, $b$ $=0.13, t(111)=0.65, p=.52$. Thus, the necessary conditions for mediation analysis have again not been met (Baron \& Kenny, 1986). Further exploration of a potential relation between 


\section{SIDE EFFECTS OF QUOTA RULES}

procedural fairness and the change in cooperation score (an OLS regression analysis with the same specification as above but including also promotion rule, categorization criterion and their interaction) led to the same pattern of results. ${ }^{16}$

With a subdivided fairness questionnaire, we were furthermore able to explore another potential explaining factor in our study: One might argue that the downgrading and replacement of the former group member is perceived as unfair by the incumbent group members, especially in quota-based promotion conditions when the upgrading violates the principles of meritocracy. In this case the negative effect of quota-based as compared to performance-based promotion on the change in cooperation of incumbent group members could be partially or entirely driven by the boycotting behavior resulting from unfair treatment of the downgraded member. However, our results do not reveal any differences between conditions regarding incumbent members' perception of the procedure applied to the downgraded former group member [4.29 (1.41), 4.34 (1.68), Mann-Whitney test: $z=-0.231, p=.82]$. Furthermore, to test whether fairness perceptions of the downgrading procedure predict the change in cooperation score for incumbent members, we conducted an OLS regression analysis on the change in cooperation score including perceived fairness of the downgrading procedure as a predictor variable and task order indicator as a control variable. The results revealed a negative, but not significant effect, $b=-.26, t(63)=-$ $0.62, p=.54 . .^{17}$

\footnotetext{
${ }^{16}$ The effect of procedural fairness perception on the change in cooperation score was again not significant, $b=.14$, $\mathrm{t}(108)=0.66, \mathrm{p}=.51$. Also, the main effect of promotion rule on the change in cooperation score remained the same, $\mathrm{b}=-1.61, \mathrm{t}(108)=-2.60, \mathrm{p}=.01$, as in an OLS regression analysis without procedural fairness as a predictor variable (see p. 27).

${ }^{17}$ A similar result was obtained when including the promotion rule, categorization criterion and their interaction in the OLS regression analysis. The relation between perceived fairness of the downgrading procedure and the change in cooperation score remained negative, but not significant, $\mathrm{b}=-0.28, \mathrm{t}(60)=-0.65, \mathrm{p}=.52$.
} 


\section{SIDE EFFECTS OF QUOTA RULES}

\subsubsection{Expectations about performance}

To test whether differences in expectations about the newcomer`s performance explain the difference in the change of cooperation between conditions, we assessed participants' expectations after the last stage of the slider task and before payoff information. ${ }^{18}$ The results of an OLS regression analysis including as explanatory variables promotion rule (quota vs. performance), categorization criterion (color vs. gender), and their interaction, revealed that incumbent members did not have significantly lower expectations regarding the performance of the newcomer when this person was promoted based on a quota as compared to performance, $b=$ $-.50, t(62)=-0.32, p=.75$. Additionally, we conducted an OLS regression on the change in cooperation score of incumbent high-status group members including expectations about performance of the incoming member as a predictor and a task order indicator as a control variable. Expectations also did not predict the change in cooperation score of incumbent members, $b=0.16, t(63)=1.57, p=.12$. Further analysis including additionally promotion rule, categorization criterion and their interaction into the above specified OLS regression revealed a positive, but non-significant relation between expectations and the change in cooperation score, $\mathrm{b}=0.17, \mathrm{t}(60)=1.60, \mathrm{p}=.12$.

\subsection{Discussion}

With Experiment 2 we aimed at replicating behavioral side effects of quota rules on group cooperation. Again, we found that individuals responded to a quota measure with a

\footnotetext{
${ }^{18}$ In total, 16 out of 66 incumbent members made at least one correct estimation of previous performance of the promoted group member.
} 


\section{SIDE EFFECTS OF QUOTA RULES}

(marginally significant) decline in cooperation compared to performance-based promotion, irrespective of the categorization criterion, supporting hypothesis 1 .

In contrast to Experiment 1, the only difference in overall fairness perceptions was found between color and gender conditions in that promotion in color conditions was in general perceived as being fairer than promotion in gender conditions. The subdivision of the questionnaire into two further fairness assessments allowed for a more fine-grained analysis of fairness perceptions. We found that when people judged the procedure with a focus on the promoted person, the promotion procedure based on quota was perceived as less fair than promotion based on performance, in line with hypothesis $2 \mathrm{a}$. These results might be due to the additional statements in the questionnaire clarifying the target of the evaluation. However, such interpretations have to be made with caution since the assessment of expectations prior to the fairness questionnaire might have also influenced the answers. As in Experiment 1, the observed effect of promotion rules on group cooperation was not mediated by fairness perceptions, neither for the overall questionnaire, nor for the version with the focus on the promoted member. Hence, there was no support for hypothesis $2 \mathrm{~b}$. Also, the analysis of the additional questions included in Experiment 2 revealed that differences in expectations concerning the performance of the promoted persons were not an explaining factor for a decline of the cooperation score.

\section{General discussion}

The participation of men and women in the workforce is still unequal. One measure that is increasingly used to introduce a higher representation of women in high-status positions, such as company executives or board members, is a mandatory gender quota. Proposers of quotas argue that besides increasing the share of women, this legislative tool comes with an additional 


\section{SIDE EFFECTS OF QUOTA RULES}

benefit: It improves team performance. With two experiments, we investigated the effects of gender quotas on a specific aspect of team performance, i.e. group cooperation.

In our experiments we relied on an incentivized, real-effort task. Unlike previous research in this area (e.g., Balafoutas \& Sutter, 2012), we investigated behavior in groups, the composition of which changed either due to a quota- or to a performance-based rule.

Furthermore, to gain more insight into the mechanism underlying possible reactions to quota rules, and different from Mollerstrom (2012), we contrasted a gender-based promotion procedure with a system that applied to an experimentally created category with no meaning or existence outside of the laboratory (i.e., group color).$^{19}$ Our results show that, although a quota system secures the achievement of a certain share of women in a specific target group, this might go along with negative impacts on group cooperation. In both experiments, cooperation behavior declined when promotion was based on quota compared to performance-based promotion (although the results were only marginally significant when treating Experiment 1 and 2 separately). This happened irrespective of the categorization type (gender or color) that was used as a criterion for a quota-based promotion. The observed difference between conditions seems to be a combination of two opposing (although not significant) changes in cooperation scores: Whereas people tended to react with an increase in cooperation when promotion was based on performance, cooperation tended to decrease in response to quota-based promotion.

Surprisingly, in both Experiment 1 and 2 the promotion procedures were perceived as fairer when implemented with artificially created minimal groups as compared to a socially meaningful group, that is gender. One possible explanation for this result is that initial

\footnotetext{
${ }^{19}$ This approach is in line with a social cognition perspective on economic behavior (i.e., Crusius, van Horen, \& Mussweiler, 2012) aiming at revealing the underlying processes of people's economic behavior.
} 


\section{SIDE EFFECTS OF QUOTA RULES}

assignments and later promotion according to color are perceived more globally as a sequence of random events that are fair from a procedural perspective. Each person starts with equal rights (before the color assignment) and what happens afterwards is merely based on luck and therefore fair (i.e., Oberholzer-Gee, Bohnet, \& Frey, 1999). In contrast, gender based assignment and promotion is based on categories that are clearly perceived to be systematic and might convey a message about the skills and abilities of participants. Although fairness perceptions were also affected by the promotion rule and categorization criteria implemented in the study, fairness evaluation did not influence group cooperation in both experiments. In addition, the expectations regarding performance of the promoted group member did not emerge as an underlying factor for the observed decline in cooperation when promotion was based on quota. The practical implications of our findings would therefore require further consideration of the processes that might underlie these effects. It is important to examine not only the effects of specific equality and diversity initiatives on relevant outcomes (e.g., group cooperation), but also to investigate the driving factors and the precise conditions that are required to avoid negative side effects of specific initiatives (such as quota rules).

\section{Limitations and future directions}

Although we took great care when designing our experiment, it still contains some weaknesses that could be addressed by future research. First, although we find a marginally significant decline in cooperation behavior as a response to a quota compared to a performancebased promotion in Experiment 1, and replicate this effect in Experiment 2, at this point we are not able to pin down the precise mechanism that explains this effect. We did not find the hypothesized mediation through perceptions of the fairness of the promotion procedure, even with an extended fairness questionnaire in Experiment 2. This might have emerged, however, 


\section{SIDE EFFECTS OF QUOTA RULES}

due to procedural choices made for these studies. For instance, a stronger effect might emerge if fairness perceptions were assessed directly after promotion and before participants interacted with the other member of the high-status group.

Second, cooperation in our study tended to increase when promotion was based on performance and decrease when it was based on a quota, resulting jointly in a negative impact of quota rules on cooperation as compared to performance based promotion. Given the fact that performance-based principles for economic status and distributing outcomes are perceived as common and fair (e.g. Kluegel \& Smith 1986; Son Hing et al. 2011, Arvey \& Renz, 1992) a comparison of a quota rule to a performance condition seems appropriate. However, also other selection criteria, such as selection based on seniority and political connections are practiced (Arvey \& Renz, 1992). Future research could contrast quota-based promotions to such selection procedures and could in addition try to isolate the pure effect of promotion by including a control condition with random promotion (promotion based on no rule).

Third, our study can only speak to reactions towards quota rules when no information is given about the performance of the newcomer. ${ }^{20}$ However, in the majority of real-life cases the information on candidates' qualifications is not provided to the co-workers. Instead, people are often uninformed about the involvement of merit in quota rules. Such lack of information might result in lower expectations regarding the performance of the incoming person promoted by quota (Heilman et al., 1992). Nevertheless, in our experiment, expectations about overall performance of persons promoted due to a quota rule as compared to a performance-based promotion did not differ and did not affect the decline in cooperation. Yet, it could be the case

\footnotetext{
${ }^{20}$ Studying individual reactions in this setting might also be relevant for some existing regulations. For instance, according to a mandatory quota rule introduced for corporate boards of German listed companies, female candidates do not need to be equally qualified as their male competitors in order to be selected according to a quota rule.
} 


\section{SIDE EFFECTS OF QUOTA RULES}

that individuals have lower expectations specifically about the cooperative performance of the other group member (i.e. their willingness to cooperate) rather than, more generally, about their overall task performance. Previous research has shown that expectations regarding the interaction partner's cooperation are a crucial determinant of one's own cooperation (e.g. Rusbult \& Van Lange, 2003), which might explain the decline in cooperation in a quotacompared to performance-based procedure. Future research could include an assessment of expectations about cooperativeness of the other group member as a potential underlying factor for reduced cooperation. Furthermore, it is worth investigating whether negative side effects can also be observed when performance is used as a (secondary) selection criterion within the discriminated group.

Furthermore, in our study the quota rule has consequences not only for the promotion of the initially disadvantaged group member, but also for the downgrading of a high-status group member. On the one hand, this ensures the internal validity of the study as group size is kept constant. On the other hand, this limits the study's external validity, since in real world settings quota admissions do not generally imply demotions of other individuals. ${ }^{21}$ However, since the main analyses did involve data from members of the privileged group only, we would expect the effect to be of minor importance. Also, the results of the fairness questionnaire regarding the procedure applied to downgraded persons, revealed no differences between the treatments. Still, we cannot rule out that this downgrading element could have reduced the external validity of our findings due to empathic concerns with the downgraded persons.

\footnotetext{
${ }^{21}$ But see the consequences of mandatory quota rules in Norway: Ahern \& Dittmar, 2012.
} 


\section{SIDE EFFECTS OF QUOTA RULES}

Finally, in many real life situations the tasks remain structurally similar before and after promotion as in our experimental design. Our results can be generalized to this kind of situations. Obviously, promotion procedures might be also applied in circumstances where the promoted person performs different tasks before and after promotion. However, given that our effects are not driven by expectations, we see no theoretical reason why the results would be different in this kind of situations. Nevertheless, this potential moderator could be critically investigated in further research. Also, our research focused on the effects of a quota system on behavior in situations in which cooperation is defined as the individual act to promote the goals of the group and where individual outcomes depend upon the performance of the other group members. This type of cooperation was subject of previous studies on the impact of quota rules on cooperation (Balafoutas \& Sutter, 2012) and it involved interdependence among group members implemented by the reward scheme and not by the task in itself (for a discussion on cooperation with task vs. reward interdependence see Wageman \& Baker, 1997). Future research can investigate the effects of quota-based promotion on cooperation in group tasks in which individual performance depends upon the efforts or skills of other group members. Such situations include a higher degree of interpersonal contact and might therefore mimic real life settings more closely. These kinds of tasks might also accrue the benefits of diversity introduced through quota-systems in ways not examined in the current research. In the current study diversity is unlikely to improve team performance in the task used. This can be concluded from recent meta-analyses showing that diversity improves performance in tasks requiring creative or innovative outcomes (Bell, Villado, Lukasik, Belau, \& Briggs, 2011) and that performance gains are limited to task-related diversity but not to bio-demographic diversity, such as gender (Horwitz \& Horwitz, 2007). These aspects do not apply to our task. Further research is needed to 


\section{SIDE EFFECTS OF QUOTA RULES}

investigate whether or not the negative effects observed in our study also generalize to such qualitatively different tasks. A further step would be to investigate the impact of quota-based systems on cooperation when task and reward interdependency are introduced jointly.

Despite some limitations, our research opens up several promising lines of enquiry. Future research might focus on identifying alternative solutions to promote gender equality, such as "soft quotas" on which the incumbent members of a group deliberately agree, or examine whether the provision of additional information (e.g. about the qualifications of candidates) lessens the negative impact on group cooperation.

The 2012 report issued by the European Commission mentioned many positive effects to be expected from the introduction of quota systems, such as better team performance, more balanced decision-making and spillover effects on other career levels. While evidence suggests that these effects are likely to emerge when comparing diverse to non-diverse environments, the question remains whether or not gender quotas are the best way to achieve these effects. As demonstrated by our research, it is not self-evident what the exact conditions are under which they will emerge. What our results do show is that any such initiative requires thorough investigation prior to implementation, at the risk of generating negative unintended effects. 


\section{SIDE EFFECTS OF QUOTA RULES}

\section{References}

Ahern, K. R., \& Dittmar, A. K. (2012). The Changing of the Boards: The Impact on Firm Valuation of Mandated Female Board Representation. The Quarterly Journal of Economics, 127, 137-197. doi: 10.1093/qje/qjr049.

Arvey, R. D., \& Renz, G. L. (1992). Fairness in the selection of employees. Journal of Business Ethics, 11, 331-340.

Balafoutas, L., \& Sutter, M. (2010). Gender, competition and the efficiency of policy interventions. IZA Discussion Paper, 4955. Retrieved from http://www.iza.org/en/webcontent/publications/papers/viewAbstract?dp_id=4955

Balafoutas, L., \& Sutter, M. (2012). Affirmative action policies promote women and do not harm efficiency in the laboratory. Science, 335, 579-582. doi: 10.1126/science.1211180

Baron, R. M., \& Kenny, D. A. (1986). The moderator-mediator variable distinction in social psychological research: Conceptual, strategic, and statistical considerations. Journal of Personality and Social Psychology, 51, 1173-1182. http://dx.doi.org/10.1037/00223514.51.6.1173

Barreto, M. (2014). Experiencing and coping with social stigma. In M. Mikulincer, P. R Shaver, J. F. Dovidio, \& J. A. Simpson (Eds.), APA Handbook of Personality and Social Psychology, 2: Group processes (pp. 473-506). Washington, D. C., WA: American Psychological Association.

Barreto, M. \& Ellemers, N. (2015). Detecting and Experiencing Prejudice: New Answers to Old Questions. In Olson, J., \& Zanna, M., (Eds.), Advances in Experimental Social Psychology, 52, 139-219. 


\section{SIDE EFFECTS OF QUOTA RULES}

Barreto, M., Ellemers, N., Scholten, W., \& Smith, H. (2010). To be or not to be: The impact of implicit versus explicit inappropriate social categorizations on the self. British Journal of Social Psychology, 49(1), 43-67. doi: 10.1348/014466608X400830

Barreto, M., \& Ellemers, N. (2003). The effects of being categorised: The interplay between internal and external social identities. European Review of Social Psychology, 14, 139170. doi: 10.1080/10463280340000045

Bell, S. T., Villado, A. J., Lukasik, M. A., Belau, L., \& Briggs, A. L. (2011). Getting specific about demographic diversity variable and team performance relationships: A metaanalysis. Journal of Management, 37, 709-743. doi: 10.1177/0149206310365001

Blader, S. L., \& Tyler, T. R. (2009). Testing \& extending the Group Engagement Model: Linkages between social identity, procedural justice, economic outcomes and extra role behavior. Journal of Applied Psychology, 94, 445-464. doi: 10.1037/a0013935

Branscombe, N. R., Ellemers, N., Spears, R., \& Doosje, B. (1999). The context and content of social identity threat. In N. Ellemers, R. Spears, \& B. Doosje (Eds.), Social identity: Context, commitment, content (pp. 35-58). Oxford: Basil Blackwell.

Branscombe, N. R., Spears, R., Ellemers, N., \& Doosje, B. (2002). Intragroup and Intergroup Evaluation Effects on Group Behavior. Personality and Social Psychology Bulletin, 28, 744-753. doi: 10.1177/0146167202289004

Brewer, M. B. (1993). Social Identity, Distinctiveness, and In-Group Homogeneity. Social Cognition, 11, 150-164. doi: 10.1521/soco.1993.11.1.150

Catalyst (2014). Increasing Gender Diversity on Boards: Current Index of Formal Approaches. NewYork: Catalyst. Retrieved from http://www.catalyst.org/knowledge/increasinggender-diversity-boards-current-index-formal-approaches 


\section{SIDE EFFECTS OF QUOTA RULES}

Chacko, T. I. (1982). Women and equal employment opportunity: Some unintended effects. Journal of Applied Psychology, 67, 119-123. doi: 10.1037/0021-9010.67.1.119

Cohen-Charash, Y., \& Spector, P. E. (2001). The Role of Justice in Organizations: A MetaAnalysis. Organizational Behavior and Human Decision Processes, 86, 278-321. doi: 10.1006/obhd.2001.2958

Crosby, F. J., Iyer, A., \& Sincharoen, S. (2006). Understanding Affirmative Action. Annual Review of Psychology, 57, 585-611. doi: 10.1146/annurev.psych.57.102904.19002

Crusius, J., van Horen, F., \& Mussweiler, T. (2012). Why process matters: A social cognition perspective on economic behavior. Journal of Economic Psychology, 33, 677-685. doi:10.1016/j.joep.2011.09.004

De Cremer, D., Tyler, T.R., \& den Ouden, N. (2005). Managing cooperation via procedural fairness: The mediating influence of self-other merging. Journal of Economic Psychology, 26, 393-406. doi:10.1016/j.joep.2004.12.004

Dufwenberg, M., \& Muren, A. (2006). Gender composition in teams. Journal of Economic Behavior \& Organization, 61, 50-54. doi:10.1016/j.jebo.2005.01.002

Ellemers, N., \& Barreto, M. (2009). Maintaining the illusion of meritocracy. In S. Demoulin, J.P. Leyens \& J. F. Dovidio (Eds.), Intergroup misunderstandings: Impact of divergent social realities (pp. 191-208). New York: Psychology Press.

European Commission. (2009). International perspectives on positive action measures. A comparative analysis in the European Union, Canada, the United States and South Africa. Luxembourg: Office for Official Publications of the European Communities. Retrieved from http://ec.europa.eu/social/main.jsp?catId=738\&langId=en\&pubId=180\&furtherPubs=yes 


\section{SIDE EFFECTS OF QUOTA RULES}

European Commission. (2012). Impact assessment on costs and benefits of imprving the gender balance in the boards of companies listed on stock exchanges. Brussels: European Commission. Retrieved from http://ec.europa.eu/justice/genderequality/files/womenonboards/impact_assesment_quotas_en.pdf

Faul, F., Erdfelder, E., Buchner, A., \& Lang, A.-G. (2009). Statistical power analyses using G*Power 3.1: Tests for correlation and regression analyses. Behavior Research Methods, 41,1149-1160. doi:10.3758/BRM.41.4.1149

Fischbacher, U. (2007). z-Tree: Zurich toolbox for ready-made economic experiments. Experimental economics, 10, 171-178. doi: 10.1007/s10683-006-9159-4

Gerhards, L. \& Siemer, N. (2014). Private versus public feedback - The incentive effects of symbolic awards. Aarhus Economics Working Paper 2014-01. Retrieved from http://pure.au.dk/portal/files/79576272/wp14_01.pdf

Gill, D., \& Prowse, V. (2012). A Structural Analysis of Disappointment Aversion in a Real Effort Competition. The American Economic Review, 102, 469-503.

Gill, D., \& Prowse, V. L. (2013). A novel computerized real effort task based on sliders. MPRA Paper No. 48081. Retrieved from http://mpra.ub.unimuenchen.de/48081/1/MPRA_paper_48081.pdf

Greiner, B. (2004). The online recruitment system ORSEE 2.0 - A guide for the organization of experiments in economics. University of Cologne, Working Paper Series in Economics, No. 10. Retrieved from http://sourceforge.net/project/showfiles.php?group_id=87875\&release_id=246447 . 


\section{SIDE EFFECTS OF QUOTA RULES}

Greiner, B. (2015). Subject Pool Recruitment Procedures: Organizing Experiments with ORSEE, Journal of the Economic Science Association 1(1), 114-125. http://link.springer.com/article/10.1007/s40881-015-0004-4

Heilman, M. E., \& Alcott, V. B. (2001). What I think you think of me: women's reactions to being viewed as beneficiaries of preferential selection. Journal of Applied Psychology, 86, 574-582. doi: 10.1037/0021-9010.86.4.574

Heilman, M. E., Block, C. J., \& Lucas, J. A. (1992). Presumed incompetent? Stigmatization and affirmative action efforts. Journal of Applied Psychology, 77, 536-544. doi: $10.1037 / 0021-9010.77 .4 .536$

Heilman, Block, C. J., Martell, R. F., \& Simon, M. (1989). Has anything changed? Current characterizations of men, women, and managers. Journal of Applied Psychology, 74, 935942. http://dx.doi.org/10.1037/0021-9010.74.6.935

Heilman, M. E., Lucas, J. A., \& Kaplow, S. R. (1990). Self-derogating consequences of sexbased preferential selection: The moderating role of initial self-confidence. Organizational Behavior and Human Decision Processes, 46, 202-216. doi:10.1016/0749-5978(90)90029-9

Heilman, M. E., Rivero, J. C., \& Brett, J. F. (1991). Skirting the competence issue: Effects of sex-based preferential selection on task choices of women and men. Journal of Applied Psychology, 76, 99-105. doi: 10.1037/0021-9010.76.1.99

Hoogendoorn, S. M., Oosterbeek, H., \& van Praag, C. M. (2013). The Impact of Gender Diversity on the performance of business teams: Evidence from a field experiment. Management Science, 59, 1514-1528. doi: 10.1287/mnsc.1120.1674 


\section{SIDE EFFECTS OF QUOTA RULES}

Horwitz, S. K., \& Horwitz, I. B. (2007). The effects of team diversity on team outcomes: A meta-analytic review of team demography. Journal of Management, 33, 987-1015. doi: $10.1177 / 0149206307308587$

International Labour Organization. (2012). Global Employment Trends 2012. Geneva: International Labour Organization. Retrieved from http://www.ilo.org/global/research/global-reports/global-employmenttrends/WCMS_171571/lang--en/index.htm

Inter-Parliamentary Union. (2014). Women in Parliament in 2013. Geneva: Inter-Parliamentary Union. Retrieved from http://www.ipu.org/pdf/publications/WIP2013-e.pdf

Ivanova-Stenzel, R., \& Kübler, D. (2011). Gender differences in team work and team competition. Journal of Economic Psychology, 32, 797-808. doi:

10.1016/j.joep.2011.05.011

Jost, J. T., \& Banaji, M. R. (1994). The Role of Stereotyping in System-Justification and the Production of False Consciousness. British Journal of Social Psychology, 33, 1-27. doi: 10.1111/j.2044-8309.1994.tb01008.x.

Jost, J. T., Pelham, B. W., Sheldon, O., \& Sullivan, B. N. (2003). Social inequality and the reduction of ideological dissonance on behalf of the system: Evidence of enhanced system justification among the disadvantaged. European Journal of Social Psychology, 33, 13-36. doi: 10.1002/ejsp.127

Kluegel, J., \& Smith, E. (1986). Beliefs about Inequality. New York: Aldine de Gruyt.

Lerner, M. J. (1980). The Belief in a Just World: A Fundamental Delusion. New York: Plenum Press. 


\section{SIDE EFFECTS OF QUOTA RULES}

Lindner, F. (2014). Decision time and steps of reasoning in a competitive market entry game. Economics Letters, 122, 7-11. doi:10.1016/j.econlet.2013.10.019

Mollerstrom, J. (2012). Quotas and Cooperation. In Preparation. Retrieved from http://scholar.harvard.edu/jmollers/publications/quotas-and-cooperation

Nacoste, R. B. (1990). Sources of Stigma: Analyzing the Psychology of Affirmative Action. Law \& Policy, 12, 175-195. doi: 10.1111/j.1467-9930.1990.tb00046.x

Nacoste, R. W. (1996). Viewpoint: Social Psychology and the Affirmative Action Debate. Journal of Social and Clinical Psychology, 15, 261-282. doi: 10.1521/jscp.1996.15.3.261

Nacoste, R. W., \& Hummels, B. (1994). Affirmative Action and the Behavior of Decision Makers. Journal of Applied Social Psychology, 24, 595-613. doi: 10.1111/j.15591816.1994.tb00602.x

Oberholzer-Gee, F., Bohnet, I., \& Frey, B. S. (1997). Fairness and competence in democratic decisions. Public Choice, 91, 89-105. doi: 10.1023/A:1004933219501

Ortmann, A., \& Tichy, L. K. (1999). Gender differences in the laboratory: evidence from prisoner's dilemma games. Journal of Economic Behavior \& Organization, 39, 327 339. doi: 10.1016/S0167-2681(99)00038-4

Plous, S. (1996). Ten myths about affirmative action. Journal of Social Issues, 52, 25-31. doi: 10.1111/j.1540-4560.1996.tb01846.x

Ritov, I., \& Zamir, E. (2014). Affirmative action and other group tradeoff policies: Identifiability of those adversely affected. Organizational Behavior and Human Decision Processes, 125, 50-60. doi:10.1016/j.obhdp.2014.04.002 


\section{SIDE EFFECTS OF QUOTA RULES}

Rusbult, C. E., \& Van Lange, P. A. M. (2003). Interdependence, interaction, and relationships. Annual Review of Psychology, 54, 351-375. doi:

10.1146/annurev.psych.54.101601.145059

Schmitt, M. T., \& Branscombe, N. R. (2002). The meaning and consequences of perceived discrimination in disadvantaged and privileged social groups. In W. Stroebe \& M. Hewstone (Eds.), European Review of Social Psychology, 12, 167-199. Chichester, England: Wiley.

Sidanius, J., \& Pratto, F. (2001). Social Dominance: An Intergroup Theory of Social Hierarchy and Oppression. Cambridge: Cambridge University Press.

Son Hing, L. S., Bobocel, D. R., \& Zanna, M. P. (2002). Meritocracy and opposition to affirmative action: Making concessions in the face of discrimination. Journal of Personality and Social Psychology, 83, 493-509.

Tajfel, H. (1970). Experiments in intergroup discrimination. Scientific American, 223, 96-102.

Tajfel, H. , \& Turner, J. C. (1979). An integrative theory of intergroup conflict. In W. G. Austin \& S. Worchel (Eds.), The social psychology of intergroup relations (pp. 3-47). Monterey, CA: Brooks-Cole.

Taylor, M. C. (1994). Impact of Affirmative Action on Beneficiary Groups: Evidence From the 1990 General Social Survey. Basic and Applied Social Psychology, 15, 143-178. doi: $10.1080 / 01973533.1994 .9646076$

Tyler, T., Degoey, P., \& Smith, H. (1996). Understanding why the justice of group procedures matters: A test of the psychological dynamics of the group-value model. Journal of Personality and Social Psychology, 70, 913-930. http://dx.doi.org/10.1037 


\section{SIDE EFFECTS OF QUOTA RULES}

Tyler, T. R., \& Blader, S. L. (2000). Cooperation in groups: Procedural justice, social identity, and behavioral engagement. Philadelphia: Psychology Press.

Tyler, T. R., \& Blader, S. L. (2003). The group engagement model: Procedural justice, social identity, and cooperative behavior. Personality and Social Psychology Review, 7, 349361. doi: 10.1207/S15327957PSPR0704_07

Unzueta, M. M., Gutiérrez, A. S., \& Ghavami, N. (2010). How believing in affirmative action quotas affects White women's self-image. Journal of Experimental Social Psychology, 46, 120-126. doi:10.1016/j.jesp.2009.08.017

Van Knippenberg, D., De Dreu, C. K. W., \& Homan, A. C. (2004). Work Group Diversity and Group Performance: An Integrative Model and Research Agenda. Journal of Applied Psychology, 89, 1008-1022. doi: 10.1037/0021-9010.89.6.1008

Vlaev, I. (2012). How different are real and hypothetical decisions? Overestimation, contrast and assimilation in social interaction. Journal of Economic Psychology, 33, 963-972. doi:10.1016/j.joep.2012.05.005

Wageman, R. \& Baker, G. (1997). Incentives and Cooperation: The Joint Effects of Task and Reward Interdependence on Group Performance. Journal of Organizational Behavior, 18(2), 139-158. doi: 10.1002/(SICI)1099-1379(199703)18:2<139::AIDJOB791>3.3.CO;2-I 


\section{SIDE EFFECTS OF QUOTA RULES}

Table 1

Descriptive statistics of change in cooperation scores by condition in Experiment 1.

\begin{tabular}{llll}
\hline & Performance & Quota & Total \\
\hline Gender & $1.14(4.23, \mathrm{n}=21)$ & $-2.00(4.22, \mathrm{n}=20)$ & $-0.39(4.47)$ \\
Color & $1.04(5.01, \mathrm{n}=26)$ & $0.71(4.33, \mathrm{n}=24)$ & $0.88(4.65)$ \\
Total & $1.09(4.63)$ & $-0.52(4.44)$ & $0.31(4.59)$ \\
\hline
\end{tabular}

Note. Individual means and standard deviations in parentheses. Negative scores indicate an increase in free-riding or decrease in cooperation. Participants who solved no slider were excluded. 


\section{SIDE EFFECTS OF QUOTA RULES}

Table 2

Regressions on change in cooperation scores and expectations predicted by condition in Experiment 1 and 2.

\begin{tabular}{|c|c|c|c|}
\hline & $\begin{array}{c}(1) \\
\text { Change in } \\
\text { Cooperation } \\
\text { Score } \\
\text { Experiment } 1\end{array}$ & $\begin{array}{c}(2) \\
\text { Change in } \\
\text { Cooperation } \\
\text { Score } \\
\text { Experiment } 2\end{array}$ & $\begin{array}{c}(3) \\
\text { Change in } \\
\text { Cooperation } \\
\text { Score } \\
\text { Pooled }\end{array}$ \\
\hline $\begin{array}{l}\text { Color } \\
(1=\text { color, } 0=\text { gender; } \\
\text { centered })\end{array}$ & $\begin{array}{c}0.610 \\
(0.889)\end{array}$ & $\begin{array}{c}-1.137 \\
(0.837)\end{array}$ & $\begin{array}{c}-0.440 \\
(0.615)\end{array}$ \\
\hline $\begin{array}{l}\text { Quota } \\
\text { (1=quota, } 0=\text { performance; } \\
\text { centered) }\end{array}$ & $\begin{array}{c}-1.683+ \\
(0.901)\end{array}$ & $\begin{array}{c}-1.565+ \\
(0.842)\end{array}$ & $\begin{array}{c}-1.611 * \\
(0.621)\end{array}$ \\
\hline Quota* Color & $\begin{array}{c}2.183 \\
(1.795)\end{array}$ & $\begin{array}{c}0.480 \\
(1.686)\end{array}$ & $\begin{array}{c}1.141 \\
(1.233)\end{array}$ \\
\hline Task order & $\begin{array}{l}1.476 * \\
(0.672)\end{array}$ & $\begin{array}{l}1.255^{*} \\
(0.517)\end{array}$ & $\begin{array}{c}1.442 * * * \\
(0.406)\end{array}$ \\
\hline $\begin{array}{l}\text { Replication } \\
(0=\text { Experiment } 1, \\
1=\text { Experiment } 2)\end{array}$ & & & $\begin{array}{c}-0.145 \\
(0.616)\end{array}$ \\
\hline Constant & $\begin{array}{l}-1.330 \\
(0.823)\end{array}$ & $\begin{array}{c}-1.250 * \\
(0.611)\end{array}$ & $\begin{array}{c}-1.275 * \\
(0.603)\end{array}$ \\
\hline Observations & 91 & 133 & 224 \\
\hline Adjusted $R^{2}$ & 0.079 & 0.037 & 0.056 \\
\hline Clusters & 47 & 67 & 114 \\
\hline
\end{tabular}

Note. Results from an OLS regression with standard errors provided in parentheses. "Task order" indicates the number of slider tasks separating both group payment schemes. Standard errors were clustered at the group level. Participants who solved no slider were excluded from the analyses.

$+p<0.10, * p<0.05, * * p<0.01, * * * p<0.001$. 


\section{SIDE EFFECTS OF QUOTA RULES}

Table 3

Regressions on procedural fairness perception by condition in Experiment 1 and 2.

\begin{tabular}{|c|c|c|c|c|}
\hline & $\begin{array}{c}(1) \\
\text { Procedural } \\
\text { Fairness } \\
\text { Experiment 1 }\end{array}$ & $\begin{array}{c}(2) \\
\text { Procedural } \\
\text { Fairness } \\
\text { Experiment 2: } \\
\text { Overall }\end{array}$ & $\begin{array}{c}(3) \\
\text { Procedural } \\
\text { Fairness } \\
\text { Experiment 2: } \\
\text { Degraded }\end{array}$ & $\begin{array}{c}(4) \\
\text { Procedural } \\
\text { Fairness } \\
\text { Experiment 2: } \\
\text { Promoted }\end{array}$ \\
\hline $\begin{array}{l}\text { Color } \\
(1=\text { color, } 0=\text { gender; } \\
\text { centered })\end{array}$ & $\begin{array}{c}0.918 * * \\
(0.272)\end{array}$ & $\begin{array}{l}0.455+ \\
(0.238)\end{array}$ & $\begin{array}{c}0.236 \\
(0.241)\end{array}$ & $\begin{array}{l}0.473 * \\
(0.218)\end{array}$ \\
\hline $\begin{array}{l}\text { Quota } \\
(1=\text { quota, } \\
0=\text { performance; } \\
\text { centered })\end{array}$ & $\begin{array}{c}-0.141 \\
(0.271)\end{array}$ & $\begin{array}{l}0.0237 \\
(0.237)\end{array}$ & $\begin{array}{c}-0.0134 \\
(0.241)\end{array}$ & $\begin{array}{c}-0.741 * * * \\
(0.218)\end{array}$ \\
\hline Quota* Color & $\begin{array}{l}1.161 * \\
(0.543)\end{array}$ & $\begin{array}{c}0.302 \\
(0.476)\end{array}$ & $\begin{array}{c}0.500 \\
(0.483)\end{array}$ & $\begin{array}{c}0.355 \\
(0.436)\end{array}$ \\
\hline Constant & $\begin{array}{c}4.668 * * * \\
(0.135)\end{array}$ & $\begin{array}{c}4.374 * * * \\
(0.119)\end{array}$ & $\begin{array}{c}4.417 * * * \\
(0.120)\end{array}$ & $\begin{array}{c}5.057 * * * \\
(0.109)\end{array}$ \\
\hline $\begin{array}{l}\text { Observations } \\
\text { Adjusted } R^{2}\end{array}$ & $\begin{array}{c}91 \\
0.127\end{array}$ & $\begin{array}{c}133 \\
0.008\end{array}$ & $\begin{array}{c}133 \\
-0.008\end{array}$ & $\begin{array}{c}133 \\
0.093\end{array}$ \\
\hline
\end{tabular}

Note. Results from an OLS regression with standard errors provided in parentheses. Model 1 refers to the data from the Experiment 1. Models 2-4 refer to the data from the Experiment 2. Participants who solved no slider were excluded from the analyses.

$+p<0.10, * p<0.05, * * p<0.01, * * * p<0.001$. 


\section{SIDE EFFECTS OF QUOTA RULES}

Table 4

Descriptive statistics of change in cooperation scores by condition in Experiment 2.

\begin{tabular}{llll}
\hline & Performance & Quota & Total \\
\hline Gender & $1.19(4.83, \mathrm{n}=36)$ & $-0.60(4.26, \mathrm{n}=35)$ & $0.31(4.61)$ \\
Color & $0.10(5.83, \mathrm{n}=30)$ & $-1.41(5.09, \mathrm{n}=32)$ & $-0.68(5.47)$ \\
Total & $0.70(5.29)$ & $-0.97(4.62)$ & $-0.15(5.03)$ \\
\hline
\end{tabular}

Note. Individual means and standard deviations in parentheses. Negative scores indicate an increase in free-riding or decrease in cooperation. Participants who solved no slider were excluded . 


\section{SIDE EFFECTS OF QUOTA RULES}

\section{Figure Captions}

Figure 1. Group means of change in cooperation scores between the first and second part of the experiment (before and after promotion) by experimental condition (categorization criterion: color vs. gender; promotion rule: performance vs. quota) in Experiment 1. Bars indicate 95\% confidence intervals.

Figure 2. Means of individual responses to the questionnaire on perceived fairness of the promotion rule by experimental condition (categorization criterion: color vs. gender; promotion rule: performance vs. quota) in Experiment 1. Bars indicate $95 \%$ confidence intervals.

Figure 3. Group means of change in cooperation scores between the first and second part of the experiment (before and after promotion) by experimental condition (categorization criterion: color vs. gender; promotion rule: performance vs. quota) in Experiment 2. Bars indicate 95\% confidence intervals.

Figure 4. Means of individual responses to the questionnaire on perceived fairness of the overall procedure (A), with a focus on the degraded person (B) and promoted person (C) by experimental condition (categorization criterion: color vs. gender; promotion rule: performance vs. quota) in Experiment 2. Bars indicate 95\% confidence intervals. 


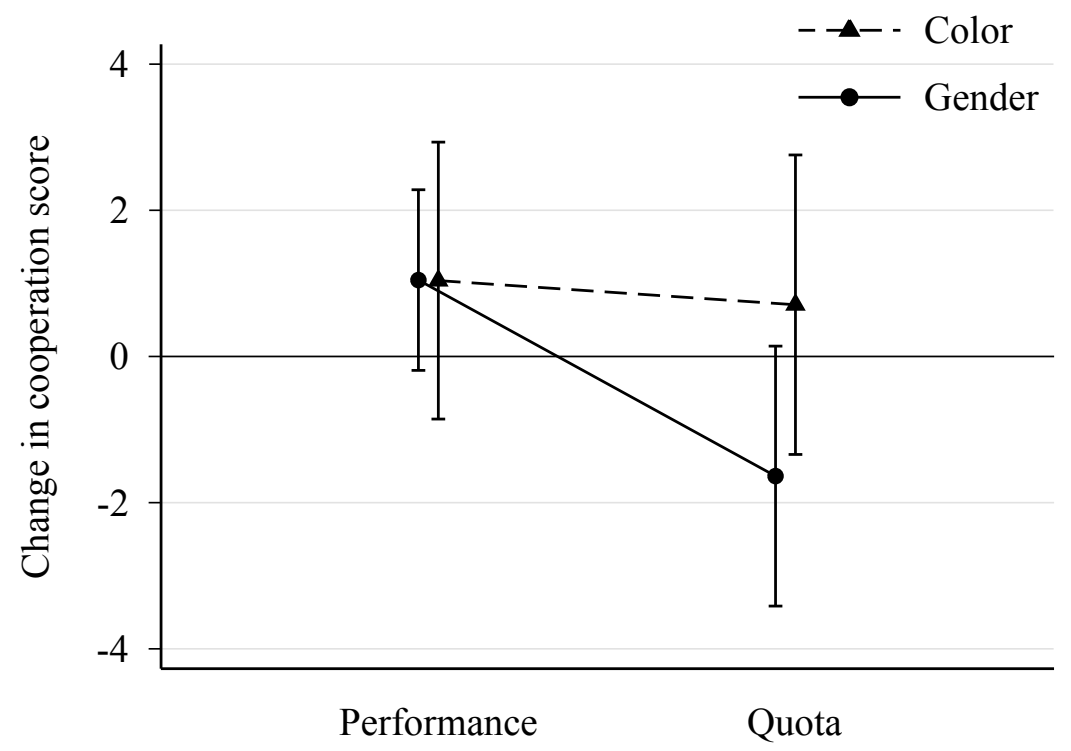




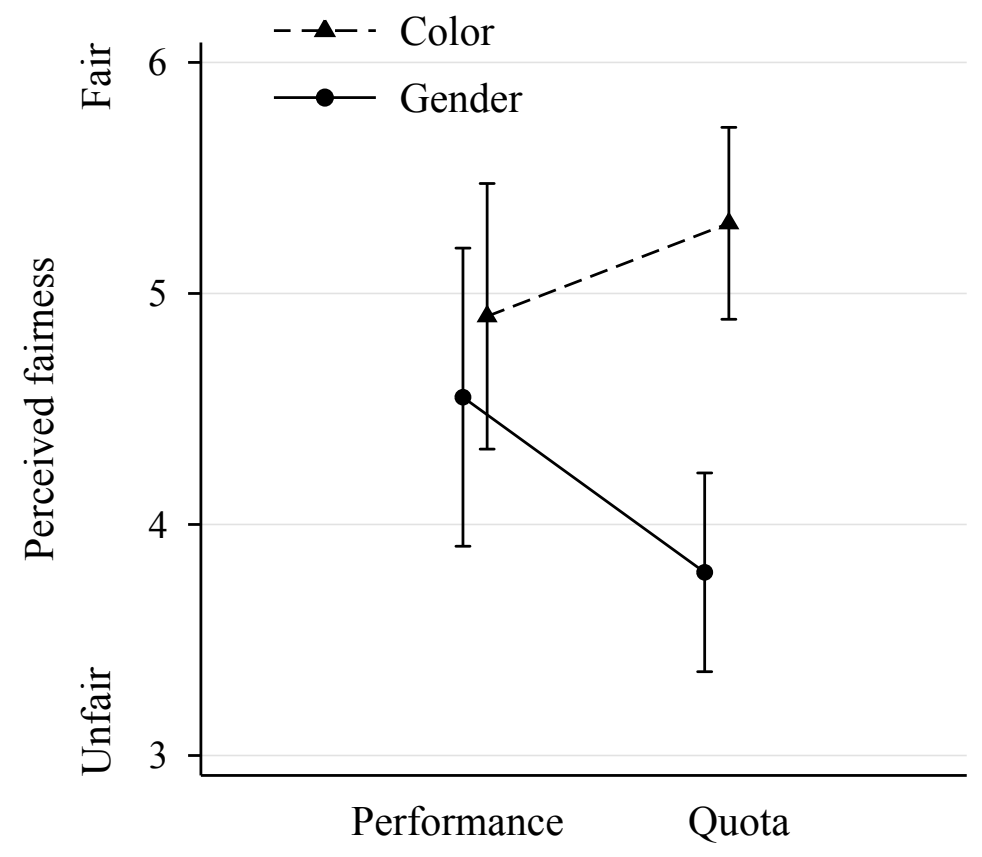




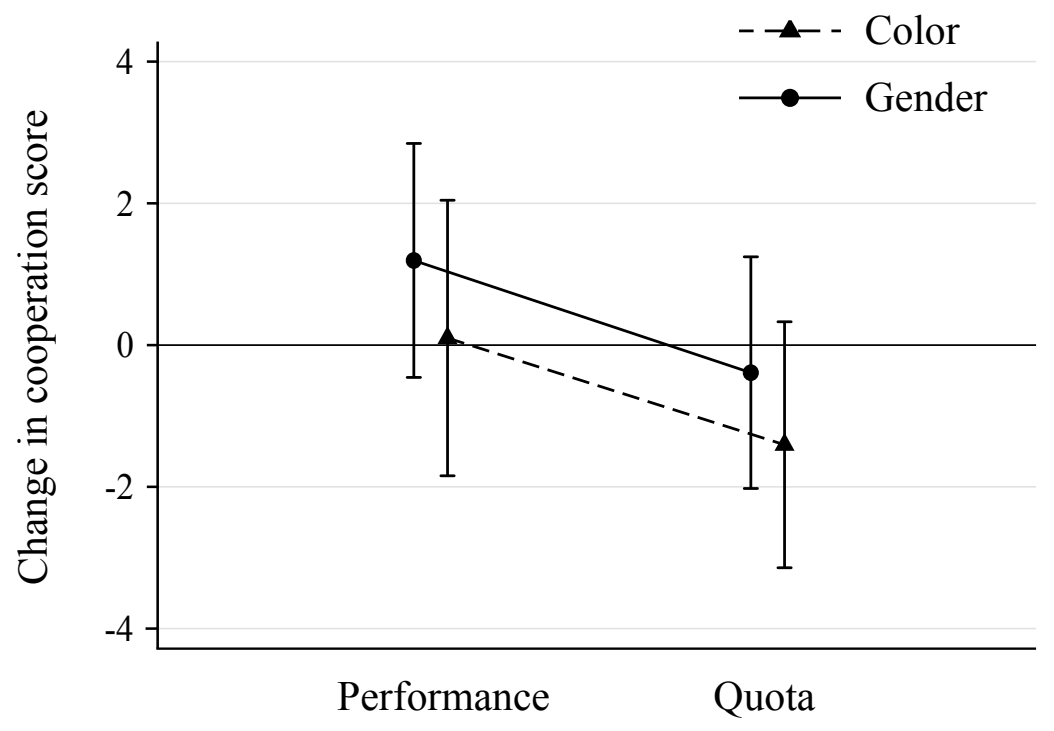




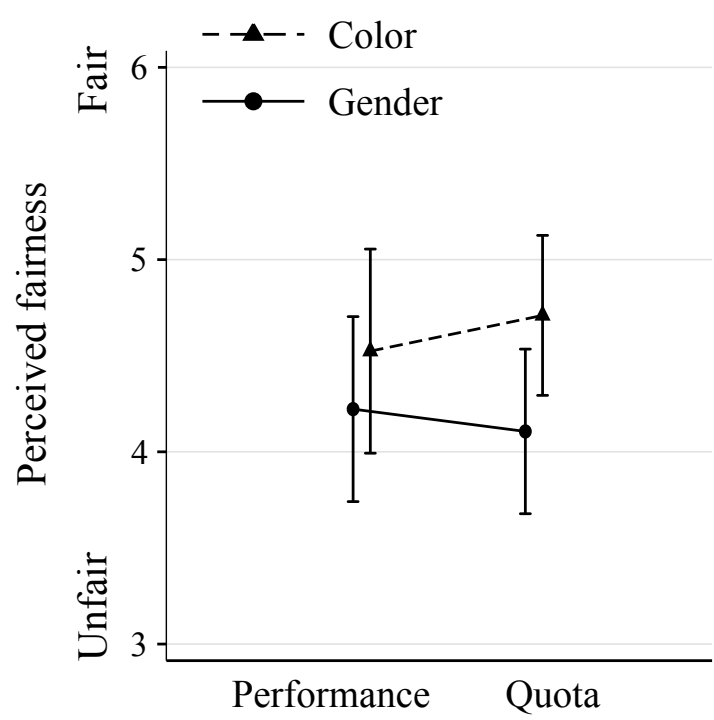

A. Perceived fairness of the overall procedure.

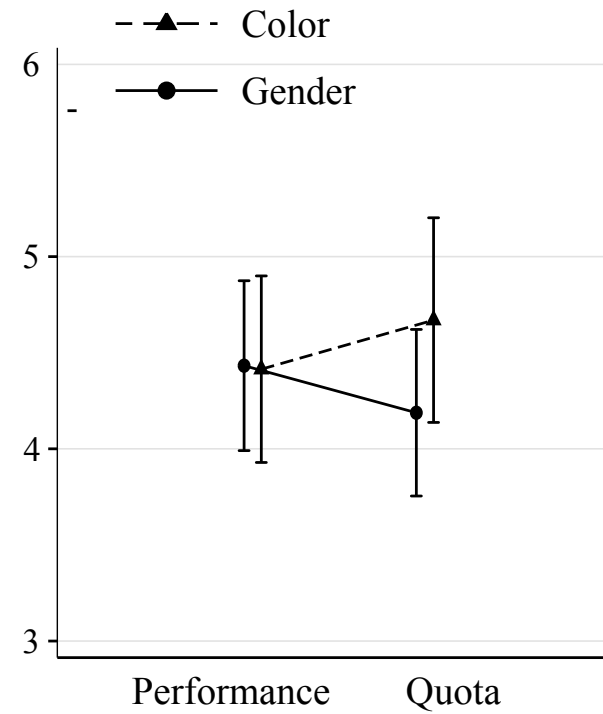

B. Perceived fairness of the procedure with a focus on the degraded person.

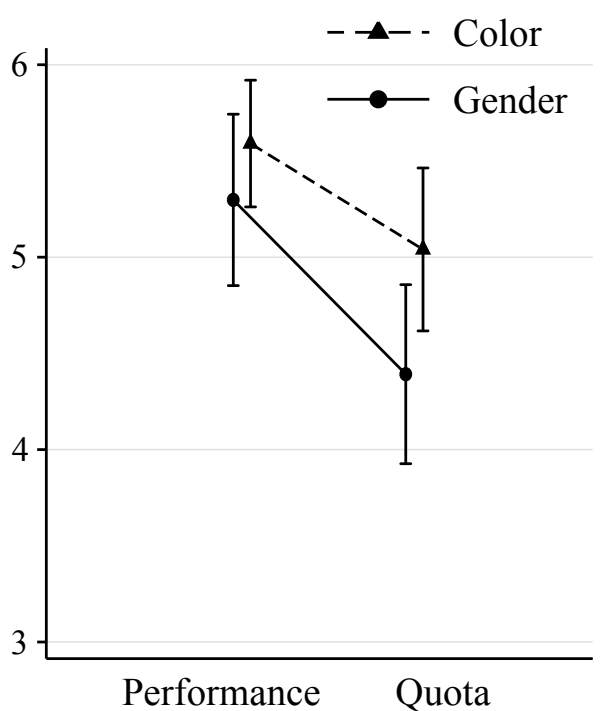

C. Perceived fairness of the procedure with a focus on the promoted person. 